\title{
DESIGN OF A COVID-19 RESPONSE FIELD HOSPITAL
}

\author{
Trisham Bharat Patil \\ Department of Mechanical Engineering \\ Worcester Polytechnic Institute, Worcester, MA
}

\begin{abstract}
This paper includes the methodology and avenues of approach involved in a comprehensive design of a Vapor Compression Cycle (VCC) for a Heating, Ventilating, and Air Conditioning (HVAC) system accommodating a mobile hospital. The development and deployment of this hospital is in response to the current global COVID-19 pandemic and its regional effect on existing local care facilities.
\end{abstract}

Keywords - Vapor Compression cycle (VCC), HVAC.

\section{INTRODUCTION}

As the COVID-19 pandemic wreaks havoc across the globe, emergency personnel and facilities have become inundated with patients as a national response various field hospital have been erected across the nation to ease the strain on these existing facilities. A field hospital's purpose can be defined as being "designed for people who have tested positive for COVID-19 and are sick enough that they need to be monitored by doctors and nurses, but not so ill that they need critical care. By treating less acute patients at these sites, hospitals will have more space to treat seriously ill patients, including those who need ventilators to help them breathe." (McCluskey, 2020).

Problem Statement- This project introduces the necessity to design an emergency response field hospital and the relative HVAC systems relevant to the location. The hospital's need to care for patients is limited to the dimension of the modules themselves and the constraints on the system. The locale chosen for this design has been identified as Shrewsbury, Massachusetts and optimized for the peak summer conditions. This seasonal design has been exclusive in the choice of the material and system conditions. All system parameters have been based off the environmental conditions for Shrewsbury and are limited to the specified season.

\section{LITERATURE}

The design of an operating refrigeration cycle is one of the most crucial and viable components to any working HVAC system. The approach to optimize the thermodynamic cycle based off the specific refrigerants properties is what gives each system its operating parameters. The classical thermodynamic refrigeration cycle includes two heat exchangers, an evaporator and a condenser, a compressor, and an expansion device, also known as a flow meter. These devices are the fundamental components of the refrigeration cycle and serve as critical assets to the cooling and pressurization processes, while also maintaining various properties specific to that hardware (i.e. constant enthalpy and/or pressure). The definition of refrigeration can be identified as the process of removing heat from a space and transferring it to another arbitrary location.

The VCC process has four main process steps. First is the compression process where the compression of the refrigerant happens to raise the temperature and pressure. Second is the condensation process where the refrigerant then flows through a condenser to get cooled at a constant pressure. Third would be the expansion process where the refrigerant enters an expansion valve to mainly decrease the pressure and temperature, and gain entropy. The fourth process step is evaporation, where heat is gained by the refrigerant and causes it to change its phase to vapor. Figure 1 shows the typical thermodynamic process of a VCC on a pressure-enthalpy chart.

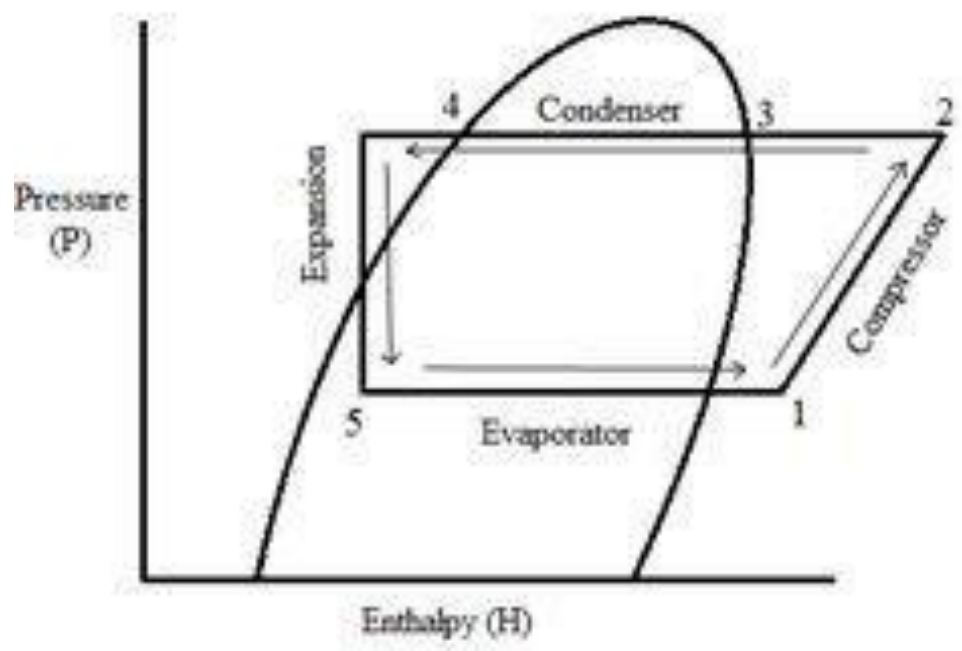

Fig. 1 Refrigeration cycle on a $\mathrm{Ph}$ diagram.

The compressor serves as the heart of the VCC and is essentially a vapor pump that increases the suction pressure to the discharge pressure level, also known as the high-side absolute pressure. The difference between the two pressures 


\section{International Journal of Engineering Applied Sciences and Technology, 2020 \\ Vol. 5, Issue 8, ISSN No. 2455-2143, Pages 242-246 \\ Published Online December 2020 in IJEAST (http://www.ijeast.com)}

can be accounted for within the compression ratio for the hardware itself. The main purpose of this device is to convert cool, saturated vapor to a superheated vapor at a much higher pressure, as described above, which is befitting to the design pressures accommodating the refrigerant properties. The compressor imparts mechanical energy on the refrigerant by increasing its pressure so it can be condensed into a liquid later on down the cycle. Its secondary function is to move the refrigerant throughout the system.

The evaporator has one of the most critical roles in the system as it serves as the medium for removing heat for a given space. This process is achieved by maintaining a cooler temperature within the evaporator's cooling coil than the space, allowing the heat, both latent and sensible, to be absorbed and removed from the space. A liquid/vapor refrigerant mixture, at a low pressure and temperature, enters the inlet of the evaporator and flashes upon absorption of the heat and is discharged as a lowpressure saturated vapor. The effectiveness of the evaporator can be measured by determining the Net Refrigeration Effect (NRE), which accounts for the difference in enthalpies between the inlet and outlet of the unit.

The condenser functions as the other heat exchanger within the system and rejects the heat absorbed in the evaporator. The refrigerant enters the condenser as a high pressure superheated vapor, undergoes a latent and sensible heat loss, and exits the unit as a saturated subcooled liquid. The rejected heat from the condenser is often dumped to an ambient atmosphere thus acting as a sink for the system. Both heat exchangers are where the greatest amounts of heat are rejected and absorbed by the system, while operating at opposing pressures.

The expansion device serves as a metering device for the refrigerant and a vehicle to effectively lower the operating pressure for the system, counteracting the pressure gained in the compressor. The expansion device divides the high-side and low-side pressures of the system with that of the compressor, while ensuring that the optimum amount of refrigerant enters the evaporator at the right time.

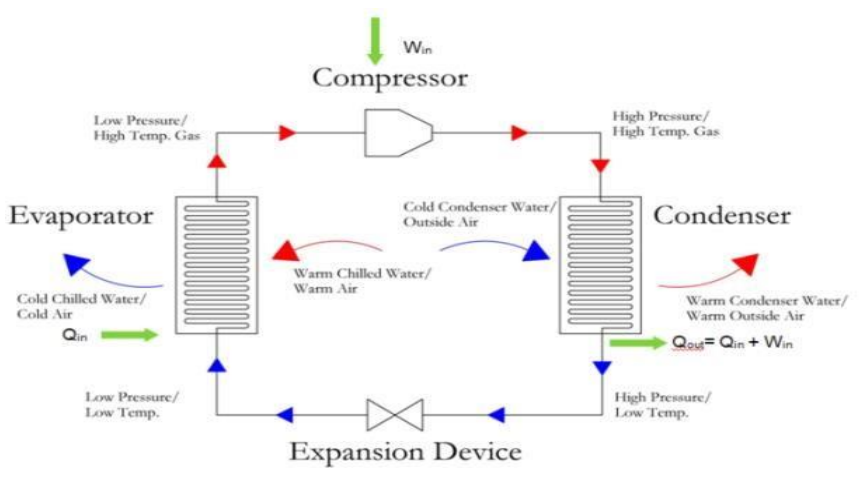

Fig. 2 VCC Cycle and hardware.
The following equations described within this section were used to formulate a system of equations that created the foundation for the analytical approach to design an appropriately sized VCC for the field hospital.

\section{Occupants}

Sensible Heat Gain: Q - p s $=\mathrm{Np} *$ qs

Latent Heat Gain: Q - pl = Np * ql

Total Heat Gain: Qtotal $=$ Q - ps + Qpl

Equipment

Lighting \& Equipment: Sensible Heat Gain/W.m ${ }^{-2}$

Conduction: $\mathrm{Qc}=\mathrm{Ka}(\Delta \mathrm{T}) / \mathrm{t}$

Evaporator: Q = Qc + Qequip + Qtotal

$$
\begin{aligned}
& \mathrm{Qe}=\text { miref (hg-hf) } \\
& \mathrm{Q}=\mathrm{UA}(\Delta \mathrm{T})
\end{aligned}
$$

Convection: $\mathrm{Q}=\mathrm{hA}(\Delta \mathrm{T})$

Condenser: $\dot{\mathrm{q}} \mathrm{c}=\mathrm{wc}+\mathrm{q}$ e

Compressor: $\mathrm{Wc}=\operatorname{mref}(\Delta \mathrm{h})$

Performance

Coefficient of performance: COP $=$ Qin $/ \mathrm{Wc}$

Heat is a form of energy, thermal, and abides by the second law of thermodynamics; that is, that energy cannot be created or destroyed. Latent heat can simply be defined as the heat that is required to change the state of a substance and not its temperature; in contrast to sensible heat, which is the heat required to change a substance's temperature, not its state. Specific heat is the amount of heat energy required to raise one pound of a substance by one-degree Fahrenheit.

\section{SYSTEM DESIGN}

For this analysis, one of the most significant assumptions made was that this vapor compression cycle can be modeled as a $\mathrm{CAV}$ and ideal cycle. Using this information, along with the selected R-134a refrigerant, the following calculations were made and illustrated within this analysis. The refrigerant's properties were retrieved from online sources and allowed for a complete determination of system performance and parameters. The system set points were determined to maintain a constant temperature throughout the space and operated in unison with the ideal filtration (HEPA) system, achieving a unilaterally exceptional MERV rating.

To accommodate the modular design of the field hospital, for the purpose of a rapid deployment, a hermetically sealed, reciprocating compressor was incorporated into the design to allow for ease of access and setup during the initial installation. 


\section{International Journal of Engineering Applied Sciences and Technology, 2020 \\ Vol. 5, Issue 8, ISSN No. 2455-2143, Pages 242-246 \\ Published Online December 2020 in IJEAST (http://www.ijeast.com)}

Below, the field hospital's dimensions and specifications are provided along with Table 1, which illustrates the local climate data used for the design of VCC.

\section{Field Hospital Specifications}

Length: $100 \mathrm{ft}$.

Width: $50 \mathrm{ft}$.

Height: $15 \mathrm{ft}$.

Occupancy Capacity: 75

\begin{tabular}{|c|c|c|}
\hline & $\begin{array}{c}\text { Temperature } \\
\left({ }^{\circ} \mathrm{F}\right)\end{array}$ & $\begin{array}{c}\text { Percent } \\
(\%)\end{array}$ \\
\hline Maximum Temperature & 101 & \\
\hline Minimum Temperature & 0 & \\
\hline $\begin{array}{l}\text { Maximum Relative } \\
\text { Humidity }\end{array}$ & & 75 \\
\hline $\begin{array}{l}\text { Minimum Relative } \\
\text { Humidity }\end{array}$ & & 15 \\
\hline Dry Bulb & & 10 \\
\hline Wet Bulb & & 50 \\
\hline
\end{tabular}

Fig. 3 Environmental conditions in Shrewsberry.

In addition to the local climate conditions a list of assumptions were compiled, serving as a baseline during the conceptual phase, and implemented during the design. This list of assumptions was primarily derived to eliminate additional variables from the project that could unnecessarily complicate the robust design of the VCC. These assumptions are provided below:

\section{List of Assumptions:}

1. Constant Air Volume (CAV) for the Heating, Ventilation, and Air Conditioning (HVAC) system

2. High Efficiency Particulate Air (HEPA) filter calculations negligible

3. Minimum Efficiency Reporting Value (MERV) negligible

4. Natural Gas consumption negligible

5. Heating and Cooling Degree Days negligible

6. Fenestrations negligible

7. Local peak Temperatures and Humidity considered for design

8. Material R and U-value(s) considered ideal

9. Cooling system only

10. Ideal refrigeration cycle and equipment performance

11. Heat transfer coefficient of evaporation equals 5000 $\mathrm{W} / \mathrm{m}^{\wedge} 2(\mathrm{~K})$

12. Heat transfer coefficient of condensation equals 2000 $\mathrm{W} / \mathrm{m}^{\wedge} 2(\mathrm{~K})$
For the sake of simplicity, the footprint of the hospital was contained to one large open space that excludes separate rooms for patients. Curtains are to be used by the medical staff to facilitate patient privacy and allow for greater customization to better cater to the floor space requirements specified by the medical personnel. This allows for a suite of floor plan configurations while maintaining consistency for the HVAC system demands and loads.

Using the American Society of Heating, Refrigerating and AirConditioning Engineers (ASHRAE) 62 standard, tailoring the requirement for a minimum of 15 cubic-feet-per-minute (CFM) for every occupant per hour, it was determined that a 5-ton air conditioning unit providing $2000 \mathrm{CFM}$ to the space would more than accommodate the requirement.

One of the first steps in the design was to calculate the U-value for the system, which was provided as a given during the project issuance. Using the given internal and external heat transfer coefficients, for the ambient air and evaporator, it allowed for a simplistic calculation for the variable. The next steps included solving for the internal heat gains of the space, including occupancy and equipment loads, while deriving an analysis for the heat gained due to conduction, convection, and radiation. This information was then used to calculate the overall load on the evaporator, or the total heat that was to be absorbed from the space; this coincided with the heat that was being removed via the condenser. A nominal mass flow rate was calculated for the refrigerant by determining the enthalpy in the gas and liquid states, this allowed for a determination of the work done by the compressor to be calculated.

Upon completion of the analytical approach to the design a pressure enthalpy diagram was plotted to visualize the system while allowing for an accurate simulation to be illustrated. Below Figure 4 depicts the completed design cycle utilizing the four main components on an isentropically ideal chart.

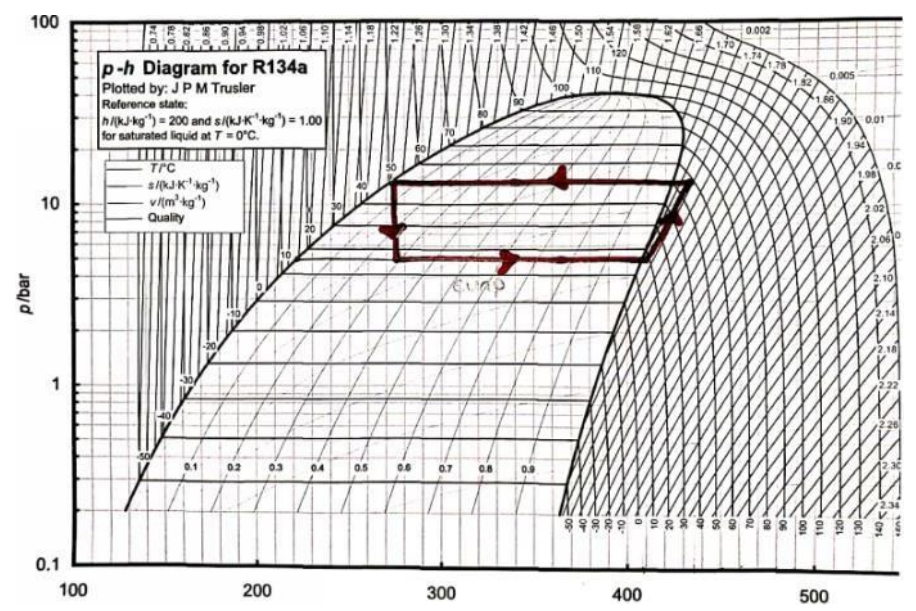

Fig. 4 System P-H diagram. 


\section{International Journal of Engineering Applied Sciences and Technology, 2020 \\ Vol. 5, Issue 8, ISSN No. 2455-2143, Pages 242-246 \\ Published Online December 2020 in IJEAST (http://www.ijeast.com)}

\section{RESULTS AND DISCUSSION.}

The calculated values obtained during the design have been provided within this section and include tabulated data that corresponds to the equations described in the previous sections of this document. This tabulated data covers the four main components of the system as well as the heat load calculations that were initially determined. Below Table 2 showcases the derived results for the system. An assumption for the equipment efficiency was made to reflect those of ideal cycles, that being that both heat exchangers are operating at $100 \%$ efficiency. However, the efficiency of the compressor was assumed to be $70 \%$.

Part of the results includes the topic of ethics concerning the design and deployment of this modular hospital. For the main aspect of this project, an immediate response to provide aid and relief to medical facilities should be prioritized, while accounting for actual costs versus gaining gross profits. That is, that the ethical design, construction, and installation of this unit, whether cloned/imitated or not, should be at a value that considers the humanitarian crisis at hand rather than the need to increase marginal profit by whatever organization(s) that are fielding them. As professionals, the dedication to quality should be at the forefront of our work, but when considering what is at hand, the design should include a priority to the patients themselves. The immediate need for support and dedication to patient care is what should drive the motivation to design such a project. Unifying under a common goal to focus on creating a vaccine and treating people suffering from this condition should be the main driver for upholding quality.

\begin{tabular}{|c|c|c|}
\hline System Component & Result & Units \\
\hline Evaporator surface area & 1.09 & $\mathrm{~m}^{2}$ \\
\hline Heat load of evaporator & 1065.63 & kW \\
\hline Condenser surface area & 1.37 & $\mathrm{~m}^{2}$ \\
\hline Heat load of condenser & 1305.85 & $\mathrm{~kW}$ \\
\hline Compressor Power & 223.81 & kW \\
\hline Coefficient of performance (COP) & 4.4 & \\
\hline
\end{tabular}

Fig. 5 Results

\section{CONCLUSION}

Using Excel, we were able to create an analytical model to calculate the VCC for each piece of hardware using local environmental conditions as external parameters for the system. The conclusions of the authors' work is presented in the appendices. The dimensions of the VCC components are appropriate for a portable hospital or field hospital. The COP between four and five is consistent with the expected.

\section{Coefficient of Performance Summary}

\begin{tabular}{|llcc|}
\hline Coefficient of Performance & & \\
Heating & $\mathrm{Q}$ & 1065.63 & $\mathrm{~kW}$ \\
Work Done & $\mathrm{W}$ & 240.22 & $\mathrm{~kW}$ \\
Coefficient of Performance & COP & 4.44 & - \\
\hline
\end{tabular}

\section{Compressor Summary}

\begin{tabular}{|c|c|c|c|}
\hline \multicolumn{4}{|l|}{ Parameters } \\
\hline Refrigerant entering enthalpy & h_1 & 408 & $\mathrm{~kJ} / \mathrm{kg}$ \\
\hline Refrigerant exiting enthalpy & h_2 & 435 & $\mathrm{~kJ} / \mathrm{kg}$ \\
\hline Refrigerant flow rate & mdot_ref & 5.80 & $\mathrm{~kg} / \mathrm{s}$ \\
\hline Efficiency & $\eta$ & 0.7 & - \\
\hline \multicolumn{4}{|l|}{ Work Done by Compressor } \\
\hline Compressor work (isentropic) & $W_{-} c_{-}$isen & 156.67 & $\mathrm{~kW}$ \\
\hline Compressor work & $W_{-}^{-} C^{-}$ & 223.81 & $\mathrm{~kW}$ \\
\hline
\end{tabular}

\section{Condenser Summary}

\begin{tabular}{|c|c|c|c|}
\hline \multicolumn{4}{|l|}{ Parameters } \\
\hline Temperature & T_i & 40 & C \\
\hline Temperature & $T_{-} \mathrm{C}$ & 50 & C \\
\hline Heat gained (evaporator load) & Q_evap & 1065.63 & kW \\
\hline Compressor work & W_c & 223.81 & kW \\
\hline Condenser heat transfer coefficient & $h_{-}$con & 2000 & $W /\left(m 2^{*} K\right)$ \\
\hline Air heat transfer coefficient & h_air & 100 & $W /(m 2 * K)$ \\
\hline \multicolumn{4}{|l|}{ Condenser Load } \\
\hline Condenser Load & $Q_{-} C$ & 1305.85 & kW \\
\hline \multicolumn{4}{|l|}{ Condenser Area } \\
\hline Conductance & U & 95.24 & $\mathrm{~m} 2 \mathrm{~N}$ \\
\hline Area in contact with outdoor air & $A_{-} C$ & 1.37 & $\mathrm{~m} 2$ \\
\hline
\end{tabular}




\section{International Journal of Engineering Applied Sciences and Technology, 2020 \\ Vol. 5, Issue 8, ISSN No. 2455-2143, Pages 242-246 \\ Published Online December 2020 in IJEAST (http://www.ijeast.com)}

\begin{tabular}{|c|c|c|c|}
\hline \multicolumn{4}{|l|}{ Hospital Parameters } \\
\hline Length & $\mathrm{L}$ & 100 & $\mathrm{ft}$ \\
\hline Width & W & 50 & $\mathrm{ft}$ \\
\hline Height & $\mathrm{H}$ & 15 & $\mathrm{ft}$ \\
\hline Wall thickness & $\mathrm{t}$ & 8 & in \\
\hline Occupancy & $\mathrm{N}$ & 75 & people \\
\hline Indoor design temperature & $T_{-}$in & 25 & C \\
\hline PVC & $k^{-}$ & 0.19 & $W\left(\left(m^{*} K\right)\right)$ \\
\hline Air & h_air & 100 & $\mathrm{~W} /\left(\mathrm{m} 2^{*} \mathrm{~K}\right)$ \\
\hline Evaportaor temperature & T_evap & 15 & C \\
\hline Liquid & $h_{-} f$ & 73.32 & $\mathrm{~kJ} / \mathrm{kg}$ \\
\hline Vapor & h_g & 256.97 & $\mathrm{~kJ} / \mathrm{kg}$ \\
\hline Evaportaor heat transfer coefficient & $h_{-}$evap & 5000 & $\mathrm{~W} /\left(\mathrm{m} 2^{*} \mathrm{~K}\right)$ \\
\hline \multicolumn{4}{|l|}{ Location Conditions } \\
\hline Outdoor peak temperature & T_out & 101 & $\mathrm{~F}$ \\
\hline \multicolumn{4}{|l|}{ Internal Heat Gain } \\
\hline \multicolumn{4}{|l|}{ Due to occupants (people) } \\
\hline Sensible heat & Q_ps & 5.385 & kW \\
\hline Latent heat & Q_pl & 3.407 & $\mathrm{~kW}$ \\
\hline Total & Q_pt & 8.792 & kW \\
\hline \multicolumn{4}{|l|}{ Due to equipment } \\
\hline Lighting & Q_I & 4.181 & kW \\
\hline Equipment & Q_q & 1.394 & kW \\
\hline Total & $Q_{-}$et & 5.574 & kW \\
\hline Total, corrected for half-volume & $Q_{-}$etc & 2.787 & kW \\
\hline \multicolumn{4}{|l|}{ Due to conduction } \\
\hline Heat due to conduction & Q_cond & 19.350 & $\mathrm{~kW}$ \\
\hline \multicolumn{4}{|l|}{ Due to convection } \\
\hline Heat due to convection & Q_conv & 1034.70 & kW \\
\hline \multicolumn{4}{|l|}{ Load on Evaporator } \\
\hline Total Heat Gain & Q_Total & 1065.63 & $\mathrm{~kW}$ \\
\hline \multicolumn{4}{|l|}{ Refrigerant Flow Rate } \\
\hline Refrigerant Flow Rate & $\dot{m}$ ref & 5.80 & $\mathrm{~kg} / \mathrm{s}$ \\
\hline \multicolumn{4}{|l|}{ Evaporator contact area } \\
\hline Conductance & U & 98.04 & $\mathrm{~m} 2 / \mathrm{W}$ \\
\hline Evaporator contact area & A & 1.09 & $\mathrm{~m} 2$ \\
\hline
\end{tabular}

[3]. R. Bartlett, et al., Understanding Building Energy Codes and Standards, PacificNorthwest National Laboratory, 2003.

[4]. L. Pérez-Lombard, et al., A review on buildings energy consumption informa-tion, Energy and Buildings 40 (3) (2008) 394-398.

[5]. J. Lausten, Energy Efficiency Requirements in Building Codes, Energy EfficiencyPolicies for New Buildings, International Energy Agency, Paris, 2008.

[6]. M. Evans, et al., Shaping the energy efficiency in new buildings: A Comparisonof Building Energy Codes in the AsiaPacific Region, Pacific Northwest National Laboratory, 2009.

[7]. Asia Business Council, Status of Energy Efficient Building Codes in Asia, 2007.

[8]. ENPER-TEBUC, Energy performance of buildings, Calculation Procedures Usedin European Countries, 2003.

[9].AustralianBuildingCodesBoard,InternationalSurveyofBuild ingEnergyCodes, Australian Greenhouse Office, Canberra, 2000 .

[10]. K.B. Janda, J.F. Busch, Worldwide status of energy standards for buildings,Energy 19 (1) (1994) 27-44.

[11]. K.B. Janda, Worldwide status of energy standards for buildings: a 2007 update,Proceedings of The Fifth Annual Improving Energy Efficiency in Commercial Buildings (IEECB), Frankfurt, Germany, April, 2008.

[12]. Hong Kong, Energy and Buildings 22 (1) (1995) 25-43.

[13]. ASHRAE Standard 90-1975, Energy Conservation in New Building Design, American Society of Heating, Refrigerating and AirConditioning Engineers, Atlanta, GA, 1975.

\section{REFERENCE.}

[1]. IEA (International Energy Agency), Energy Balances of OECD Countries - 2010edition, Paris, 2010.

[2]. L. Pérez-Lombard, et al., A review of benchmarking, rating and labelling con-cepts within the framework of building energy certification schemes, Energyand Buildings 41 (2009) $272-278$ 